\title{
Regional Differences of Serotonin-Mediated Synaptic Plasticity in the Chicken Spinal Cord with Development and Aging
}

\author{
Ling Chen, Kayoko Hamaguchi, Shun Hamada and Nobuo Okado \\ Neurobiology Laboratory, Department of Anatomy, Institute of Basic Medical Sciences, \\ University of Tsukuba, Tsukuba, Ibaraki 305, Japan
}

\section{SUMMARY}

Previous studies in our laboratory $/ 3,17 /$ have demonstrated that serotonin (5-HT) appears to have a trophic-like effect in enhancing synapse formation and maintenance in both the developing and the adult central nervous system. In the present study, we focused on age-related changes in the density of the axosomatic and axodendritic synapses and the number of 5-HTpositive fibers in the chicken spinal cord, with special reference to differences between the ventral (laminae VII and IX) and the dorsal (lamina I) horn. At 1 week posthatching (P1W), a transient overproduction of synapses and 5-HT-immunoreactive fibers occurred in lamina IX; all parameters had returned to their initial levels by 1 month post-hatching (P1M). The density of synapses further decreased by about $40 \%$ between P6M and P2Y (2 years posthatching). Although the magnitude of the transient increase in lamina VII was less than that in lamina $I X$, the changing pattern of the synapses and the 5-HT-positive fibers was similar in both regions. In the ventral horn, thin 5-HT-positive fibers were most prominent at P1W and then decreased with development; thin 5-HT-positive fibers were still found at P6M but had almost disappeared by P2Y. By contrast, at P2Y the density of the synapses and the 5-HT-positive fibers in the dorsal horn was even higher than that of younger animals.

\footnotetext{
Reprint address:

Nobuo Okado, Neurobiology Laboratory

Department of Anatomy, Institute of Basic Medical Sciences University of Tsukuba, Ibaraki 305, Japan

Tel/Fax: +81-298-53-6960
}

Reduction of 5-HT levels in P2Y-old chickens by p-chlorophenylalanine (pCPA) administration decreased the synaptic density in lamina $I$ but not in lamina IX. The results of this study demonstrate that 5-HT-mediated synaptic plasticity is markedly different in the ventral and dorsal horns of the aged chicken. In the ventral horn, synaptic plasticity reached a maximum at about $P 1 W$, remained stable in the young-adult period, and then finally disappeared in the aged chicken. Conversely, the results suggest that in the dorsal horn, 5-HT fibers continue to mediate the trophic influence on synaptic plasticity even in the old chicken.

\section{KEY WORDS}

synaptic plasticity, 5-HT, dorsal horn, ventral horn

\section{INTRODUCTION}

Chubakov and colleagues /4/ first demonstrated using in vitro preparations that serotonin (5-HT) has a trophic-like role in facilitating the formation of chemical synapses. Subsequent in vivo studies in our laboratory $/ 17,3 /$ have shown that 5 -HT enhances synapse formation and maintenance in both the developing and the mature central nervous system (CNS). The synaptic density decreases in a dose-dependent fashion in the presence of 5-HT depletors with different pharmacokinetics; at the maximum dose, almost $70 \%$ of the synapses disappear within one week after the decrease in the 5-HT level.

To exclude the possibility that synaptic loss occurs by nonspecific side effects of 5-HT depletors, Niitsu et al $/ 16 /$ identified the 5-HT 
receptor subtype mediating the facilitator role of 5-HT. In the chicken embryo, the number of synapses in the ventral horn of the spinal cord could be artificially manipulated by administering a 5-HT2A antagonist or agonist or both.

Because 5-HT fibers are distributed diffusely in diverse regions of the CNS, the putative role of 5 -HT in regulating the number of synapses is important for understanding not only brain function but also the background mechanism for synaptic plasticity. In our previous line of studies $/ 3,17 /$, we needed more information to understand the regulatory mechanism of 5-HT-mediated synaptic plasticity. Hence, we undertook the present study to clarify the following points. (1) We attempted to analyze in detail the changes in synaptic density with development and aging. (2) We expected to ascertain whether 5-HT-mediated synaptic plasticity is maintained in the aged chicken. As a special interest was directed toward the differences between the motor and sensory systems, we analyzed data from both the anterior horn (laminae VII and IX) and dorsal horn (lamina I).

\section{METHODS}

\section{Animals}

Over 100 White Leghorn chickens were used in this study. The chickens were examined at posthatching (P) days P0D, P1W (1 week), P2W, P1M (1 month), P2M, P6M, and P2Y (2 years).

\section{Tissue preparation}

Chickens were deeply anesthetized with an overdose of chloropent and then perfused from the ascending aorta with a small amount of saline followed by a fixative. A fixative composed of 0.1 $M$ phosphate buffer containing $4 \%$ paraformaldehyde and $0.15 \%$ picric acid was used for immunohistochemical studies. For electron microscope studies, the fixative buffer contained $2.5 \%$ glutaraldehyde and $2 \%$ paraformaldehyde. Immediately after the perfusion fixation, lumbosacral spinal-cord segment 3 was removed and immersed in the appropriate fixative for $12 \mathrm{hr}$ at $4^{\circ} \mathrm{C}$. For the immuno-histochemistry studies,
40- $\mu \mathrm{m}$-thick transverse sections of the spinal cord were cut on a freezing microtome. Free-floating sections were reacted with an antibody against 5-HT, using the ABC method /23/. That immunohistochemical staining tends to vary among animals or even within single sections is widely believed. To ensure staining consistency, immunohistochemistry preparations were carefully processed in our laboratory. Perfect perfusion fixation and constant agitation of the sections during the staining process are necessary. For quantitative analyses, we selected several of the best-stained sections.

For electron microscope studies, spinal segments were transversely cut to a thickness of about $1 \mathrm{~mm}$, osmificated, and then embedded in Epon. Semithin plastic sections, $2-4 \mu \mathrm{m}$ thick, were cut with a glass knife and stained with toluidine blue. The sections were re-embedded in Epon after observation under a light microscope to ascertain tissue orientation. Except for the regions to be examined, the reembedded sections were trimmed.

\section{Pharmacological experiment}

To decrease the amount of 5-HT in the spinal cord of P2Y-old chickens, four injections of p-chlorophenylalanine (pCPA) $(800 \mathrm{mg} / \mathrm{kg}$ body weight) were given intraperitoneally over a period of 7 days (days 1,2,4, and 6). Control animals received saline injections on the same days. The chickens were perfused with the fixative for electron-microscope studies. We compared the data on P2Y-yr-old chickens with data on P1W-old and P6M-old chickens that were examined in a previous study $/ 17 /$.

\section{Quantitative analyses}

Four animals (either control or experimental) were used for each stage. For each animal, electron micrographs were taken of each axosomatic and axodentritic synapse, from the dorsolateral part of the lateral motor column, at a primary magnification of $\times 5000$. From each animal, 10-20 photographs of both types of synapses were taken from two reembedded, semi-thin sections. The negatives were enlarged on printing papers, and the final magnification reached $\times 9000$. Synapses were identified as profiles having aggregates of synaptic 
Table 1

5-HT-immunoreactive varicosities and synaptic densities in the chicken spinal cord

\begin{tabular}{ccccc}
\hline \multirow{2}{*}{ Lamina } & & \multicolumn{2}{c}{ Synaptic Density $^{\mathbf{a}}$} \\
\cline { 3 - 5 } & Age & 5-HT Immunoreactivity & Axosomatic $^{\mathrm{b}}$ & Axodendritic $^{\mathrm{c}}$ \\
\hline I & P0D & $71.72 \pm 08.14(42$ & $0.07 \pm 0.07(54)$ & $28.17 \pm 07.42(36$ \\
& P1W & $181.94 \pm 16.29(36$ & $0.13 \pm 0.09(50)$ & $50.49 \pm 12.69(45$ \\
& P2W & $110.80 \pm 10.04(48$ & $0.11 \pm 0.09(40)$ & $36.55 \pm 07.68(40$ \\
& P1M & $82.50 \pm 12.34(40$ & $0.11 \pm 0.07(48)$ & $38.57 \pm 06.76(44$ \\
& P2M & $75.00 \pm 08.05(36$ & $0.10 \pm 0.14(50)$ & $41.91 \pm 08.29(42$ \\
& P6M & $81.40 \pm 05.04(45$ & $0.18 \pm 0.11(42)$ & $40.88 \pm 10.03(32$ \\
& P2Y & $117.40 \pm 07.64(62$ & $0.16 \pm 0.09(60)$ & $44.75 \pm 05.60(60$ \\
VII & & & & \\
& P0D & $55.00 \pm 09.97(62$ & $0.21 \pm 0.12(108$ & $17.74 \pm 03.71(64$ \\
& P1W & $134.00 \pm 08.65(40$ & $0.36 \pm 0.13(101$ & $24.21 \pm 04.44(64$ \\
& P2W & $84.00 \pm 10.42(64$ & $0.26 \pm 0.11(78)$ & $15.91 \pm 08.70(44$ \\
& P1M & $58.60 \pm 09.16(64$ & $0.23 \pm 0.11(68)$ & $16.94 \pm 05.01(48$ \\
& P2M & $73.00 \pm 05.69(48$ & $0.19 \pm 0.11(56)$ & $15.57 \pm 04.19(24$ \\
& P6M & $55.00 \pm 11.24(52$ & $0.24 \pm 0.11(60)$ & $14.34 \pm 04.38(38$ \\
IX & $52.00 \pm 09.61(44$ & $0.20 \pm 0.13(66)$ & $15.56 \pm 03.55(34$ \\
& & & & \\
& P2Y & & & $23.59 \pm 05.53(54$ \\
& P0D & $96.00 \pm 13.02(60)$ & $0.28 \pm 0.12(118$ & $36.47 \pm 09.33(52$ \\
& P1W & $334.00 \pm 40.43(100$ & $0.51 \pm 0.15(102$ & $25.06 \pm 04.92(52$ \\
& P2W & $154.00 \pm 14.45(64)$ & $0.33 \pm 0.14(100$ & $18.10 \pm 03.77(42$ \\
P1M & $100.00 \pm 13.99(64)$ & $0.28 \pm 0.14(64)$ & $18.58 \pm 03.90(24$ \\
& P2M & $92.00 \pm 10.49(48)$ & $0.24 \pm 0.16(52)$ & $18.19 \pm 04.33(48$ \\
P6M & $102.00 \pm 15.22(52)$ & $0.30 \pm 0.07(60)$ & $12.64 \pm 03.54(36$
\end{tabular}

${ }^{a}$ Means \pm standard deviation (no. in parentheses indicates no. micrographs counted). ${ }^{b}$ No. synapses per $1 \mu \mathrm{m}$ somatic membrane. No. synapses in $200 \mu \mathrm{m}^{2}$. P=posthatching, $\mathrm{D}=$ day, $\mathrm{M}=$ month, $\mathrm{Y}=$ year

vesicles and a membrane specialization that was characteristic of an active zone. Axosomatic synapses were located on the somatic profiles. The density of axosomatic synapses was expressed as the number of synapses per $1 \mu \mathrm{m}$ of somatic membrane. Axodendritic synapses were counted in the area of $200 \mu \mathrm{m}^{2}$ in the neuropil. The synaptic density was examined in laminae I, VII, and IX. The data of the synaptic density on POD (lamina IX), P1W (laminae I, VII, IX), and P6M (lamina IX) gathered in a previous study /17/ were compared with the new data from the present study. The results are presented in Table 1.

Fibers positive for 5-HT consisted of varicosities and thread-like parts interconnecting the varicosities. Although we could identify the varicosities in light-microscopic observations (see Figure 1), we did not always recognize the fine, thread-like parts. Therefore, we carried out quantitative analyses on the density of the 5-HT fibers by counting the number of varicosities in a unit area $\left(1000 \mu \mathrm{m}^{2}\right)$, using a light microscope equipped with an oil-immersion objective lens $(\times 100)$ and a drawing tube. We counted the number of varicosities from five regions of each lamina; the mean represents the value of one animal. We used ANOVA for statistical comparison between each pair.

\section{RESULTS}

\section{Structural changes of 5-HT-positive fibers}

Between P6M and P2Y, the number of thin 5-HT-immunoreactive fibers in lamina IX (Figure 1, small arrows) that were not counted in the quantitative study decreased by P2Y. When compared with their appearance at $\mathrm{P} 6 \mathrm{M}$, the thick varicose fibers surrounding the somal profiles of 

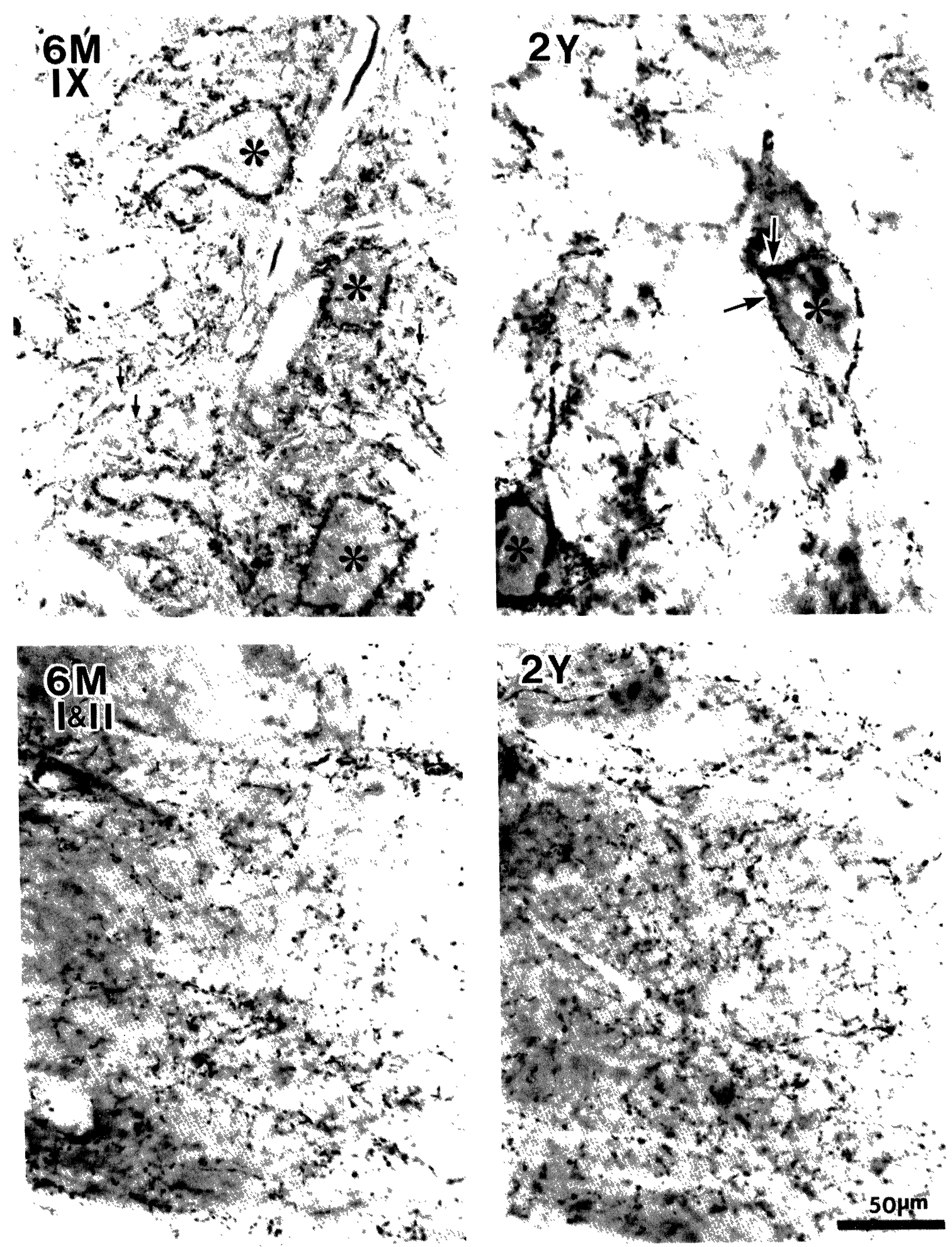

Fig. 1: Photomicrograph of 5-HT-positive profiles in lamina IX (upper) and laminae I and VII (lower) at P6M-old (left column) and P2Y-old (right column) chickens. ${ }^{*}$ indicates motoneuron soma. Section thickness $=40 \mu \mathrm{m}(\mathrm{ABC}$ method). Large arrows indicate thick 5-HT-immunoreactive varicose fibers; small arrows indicate thin 5-HT-immunoreactive fibers. 
large-size neurons (Fig. 1, large arrows) appeared to be enlarged or swollen at P2Y. In laminae I and II, neither the ratio of thin fibers versus thick varicosities nor general appearance of 5-HT immunoreactive fibers changed between P6M and P2Y.

Table 1 shows the chronological changes in number of 5-HT-positive varicosities counted in the immunohistochemical preparations. The results are presented in graphic form in Figure 2. In all three laminae studied here, the density of varicosities reached a maximum value at $\mathrm{P} 1 \mathrm{~W}$ and then decreased to near-initial values around P1M. The density of 5-HT varicosities in lamina I, but not those in laminae VII and IX, showed a moderate increase at $\mathrm{P} 2 \mathrm{Y}$.

\section{Synaptic density at different posthatching ages}

The chronological changes in the density of 5-HT immunoreactive varicosities and synapses in the chicken spinal cord are presented in Table 1 and shown in graphic form in Figure 2. The sharp rise in the density of both the axodendritic and axosomatic synapses seen in all three laminae was most characteristic of lamina IX. After the first peak, the synaptic density in lamina IX generally decreased with development and aging, except for a small transient increase in the density of the axosomatic synapses at P6M that did not exceed the initial level. The pattern of changing synaptic-density in lamina VII was similar to that of lamina IX. After a moderate increase at $\mathrm{P} 1 \mathrm{~W}$, the density of the axosomatic synapses in lamina I did not decrease much at P2W. Rather than decreasing further, the density of both synapses in lamina I were higher at $\mathrm{P} 2 \mathrm{Y}$ than at P2W.

\section{Synaptic density in pCPA-treated chickens}

The effect of pCPA on eliminating 5-HT differs greatly among different species and among different regions of the CNS. In a previous study $/ 17 /$, we obtained the maximum effect in the chicken spinal cord by injecting $800 \mathrm{mg} \mathrm{pCPA} / \mathrm{kg}$ body weight. Data from P2Y-old chickens in the present study were compared with those from P1W-old and P6Mold chickens studied in $/ 17 /$. Table 2 shows that relative to untreated control animals, the
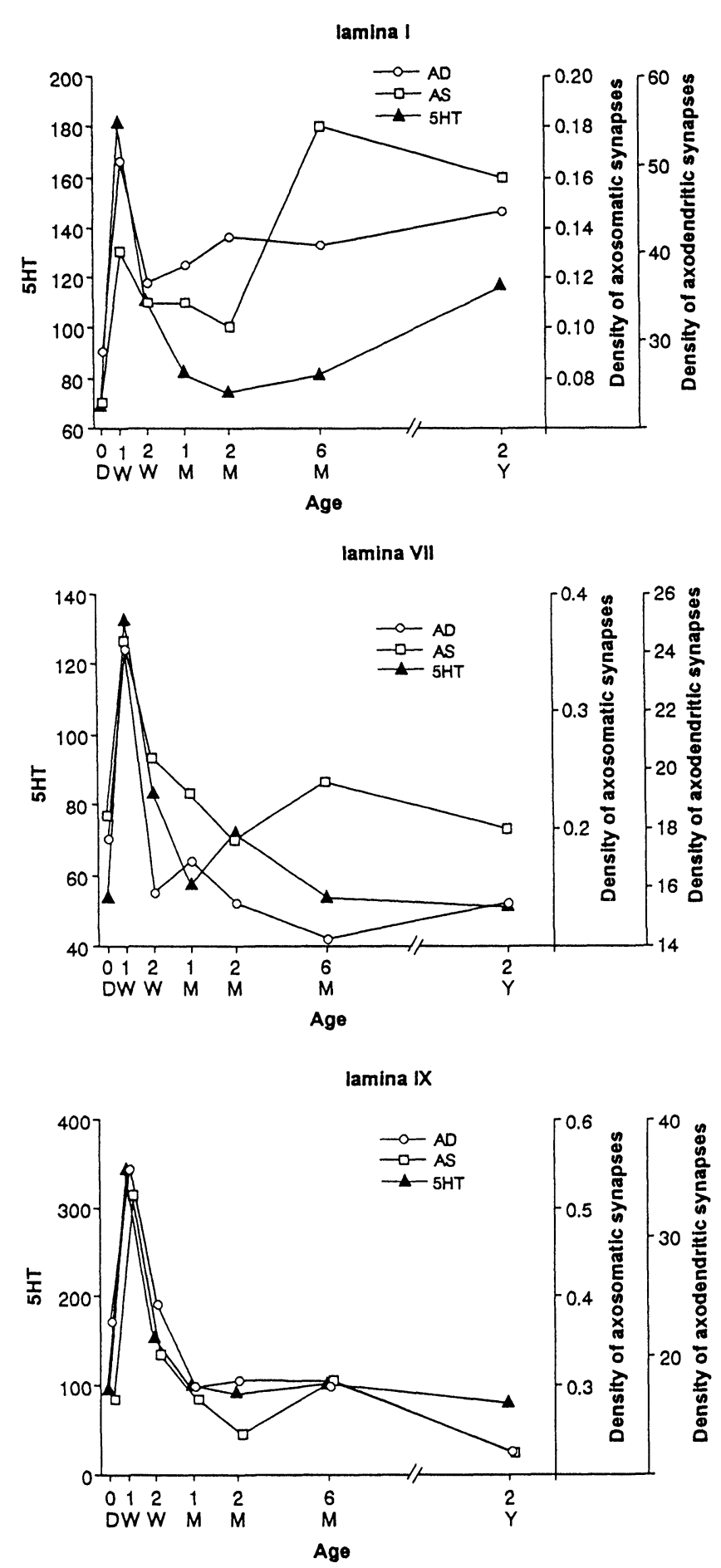

Fig. 2: Changes in 5-HT-immunoreactive varicosities and synaptic density with development and aging. $\mathrm{AD}=$ axodendritic, $\mathrm{AS}=$ axosomatic, $\mathrm{D}=$ day, $\mathrm{Y}=$ year, $\mathrm{W}=$ week, $\mathrm{M}=$ month 
Table 2

Synaptic densities in pCPA-treated chickens and untreated control animals ${ }^{a}$

\begin{tabular}{|c|c|c|c|c|c|c|c|}
\hline \multirow[t]{2}{*}{ Lamina } & \multirow[t]{2}{*}{ Age } & \multicolumn{3}{|c|}{ Axosomatic $^{\mathrm{b}}$} & \multicolumn{3}{|c|}{ Axodendritic ${ }^{\mathrm{c}}$} \\
\hline & & Untreated & pCPA & $\mathbf{P}$ & Untreated & pCPA & $\mathbf{P}$ \\
\hline \multirow[t]{2}{*}{ I (SP) } & P1W & $0.13 \pm 0.09(49)$ & $0.09 \pm 0.08(47)$ & $0.000131 \%$ & $50.49 \pm 12.69(45)$ & $35.84 \pm 12.88$ & $0.000129 \%$ \\
\hline & $\mathrm{P} 2 \mathrm{Y}$ & $0.16 \pm 0.09(60)$ & $0.12 \pm 0.08(41)$ & $0.027925 \%$ & $44.75 \pm 5.60(60)$ & $38.86 \pm 6.38(32)$ & $0.000514 \%$ \\
\hline \multirow[t]{2}{*}{ IX (SP) } & P1W & $0.51 \pm 0.15(102)$ & $0.16 \pm 0.06(91)$ & 0.0001 & $36.47 \pm 9.33(51)$ & $14.04 \pm 4.81(48)$ & $0.000161 \%$ \\
\hline & $\mathrm{P} 2 \mathrm{Y}$ & $0.22 \pm 0.13(67)$ & $0.22 \pm 0.13(101)$ & $0.9599 \quad 0 \%$ & $12.64 \pm 3.54(36)$ & $13.10 \pm 3.54(41)$ & $0.5734 \pm 1 \%$ \\
\hline
\end{tabular}

${ }^{a}$ Means \pm standard deviation (No. in parentheses indicates no. electron micrographs counted).

${ }^{b}$ No. synapses per $1 \mu \mathrm{m}$ somatic membrane. ${ }^{\circ}$ o. synapses in $200 \mu \mathrm{m}^{2}$.

$\mathrm{P}=$ posthatching, $\mathrm{D}=$ day, $\mathrm{M}=$ month, $\mathrm{Y}=$ year, $\mathrm{SP}=$ spinal cord, $\mathrm{P}=$ posthatching, $\mathrm{lW}=$ one week, $2 \mathrm{Y}=$ two years

axosomatic and the axodendritic synaptic densities did not change in lamina IX of P2Y-old, pCPAtreated chickens (see 'Methods'). In lamina I, however, the density of the axosomatic synapses in pCPA-treated chickens decreased by $25 \%$ $(p=<0.05)$ and the density of the axodendritic synapses decreased by $14 \%(p=<0.01)$ relative to untreated animals.

\section{DISCUSSION}

\section{Changes in 5-HT varicosities and synaptic density with development and aging}

The results of the present study have demonstrated differences between the dorsal and ventral horns in both the magnitude and duration of 5-HT-mediated synaptic plasticity. In lamina IX, the synaptic density transiently increased at P1W. Although the magnitude of the transient increase in lamina VII was less than that in lamina IX, the changing pattern of both synapses and of 5-HT-positive fibers was similar to that in lamina IX. Overproduction of synapses was especially prominent in lamina IX. Although synaptic overproduction has long been considered a structural background for generating plasticity in the critical period of development $/ 2,7,8,21 /$, a substance for regulating the number of synapses in the brain was identified only recently, when a study in our laboratory demonstrated that 5-HT facilitates synaptic overproduction $/ 17 /$.

Overexpression of 5-HT (monoamines) during development has been found in regions of the CNS other than the chicken spinal cord /10,18/. Using ultrastructural markers of the monoamine 5-hydroxydopamine, Kristt /12/ demonstrated that $20 \%$ to $30 \%$ of all synapses are monoaminergic in the somatosensory cortex of rodents in the first postnatal week and that the ratio decreases thereafter. Aberrant 5-HT fibers appeared around postnatal day 10 in the barrel fields of the cerebral cortex of rodents $(5 / 6)$. A transient increase of 5-HT fibers in the spinal cord of rats has also been reported /19/. During the critical period of development, the transient overexpression of 5-HT shown in various regions of the CNS may also have a trophic-like role in producing synaptic overproduction.

The synaptic-density pattern seen in lamina I was different from those of laminae VII and IX. When compared with the ventral horn at P1W, the magnitude of synaptic overproduction in lamina I was less prominent. Moreover, the synaptic density in lamina I did not decrease further after P2W as it did in the ventral horn. At P2Y the synaptic density in lamina IX decreased to about $50 \%$ of that seen at P6M, whereas in lamina I, the synaptic density of P6M-old and P2Y-old chickens showed very little change. After pCPA injections, the patterns of changes in synaptic density in the dorsal versus the ventral horn were different as well.

Because the increase-decrease pattern in the density of synapses at the critical period of development is conspicuous, much attention has been paid to the synaptic overproduction as one mechanism generating plasticity in the developing brain. Although synaptic density does not change for a long time (weeks or months), 5-HT-facilitated 
synapse formation is assumed for synaptic turnover or remodeling in the adult CNS.

The results of our recent study /16/ demonstrated that synapse formation is mediated by 5-HT2 receptors The 5-HT2 receptors in the neocortex decrease gradually with aging $/ 9,15 /$. The brain shows an enormous loss of 5-HT2 receptors in Alzheimer's disease $/ 1,20,22 /$. In such situations, synaptic loss may occur in the affected brain because the ability of synaptic recruitment is lost. Therefore, we would like to emphasize that synaptic plasticity mediated by 5 -HT is an important issue not only in the developing but also in the adult and the aging brain.

\section{Thin versus thick 5-HT-positive fibers}

The thin 5-HT-positive fibers in lamina IX of P1W-old chickens were most frequently located in the neuropil, where synapse formation is accelerated to the maximum. Although their numbers decreased after P1W, thin fibers were still seen in P6M-old chickens. By contrast, thin 5-HT-positive fibers were not found in lamina IX of P2Y-old chickens, who appeared to have lost synaptic plasticity. Such findings may suggest an involvement of thin, 5-HT-positive fibers in the trophic effects for synapse formation.

Most of the enlarged or swollen varicose 5-HT fibers were found around somal profiles of motoneurons in lamina IX of P2Y-old-chickens. Steinbusch and colleagues $/ 24 /$ demonstrated similar changes in the 5-HT fibers of aged (28-month-old) rats. Such changes in aged chickens and rats may represent degenerating fibers because they appear structurally similar to the changes seen in 5,7dihydroxytryptamine-induced denervation $/ 25,26 /$.

Several groups $/ 11,13,14,27 /$ have reported different properties for each type of 5-HT fiber. In the neocortex of the rat $/ 11 /$ and the monkey $/ 27 /$, the two types of 5-HT fibers have dissimilar regional and laminar patterns of distribution. When compared with thick fibers innervating specific regions or laminar structures, fine 5-HT fibers are distributed more diffusely. These two fiber types exhibit differential vulnerability to neurotoxic amphetamine derivatives. Thin fibers degenerate more easily, whereas thick fibers are consistently spared $/ 14 /$. Another difference between the two types of fibers is that thin and thick fibers arise from different cells of origin: the dorsal and median raphe nuclei, respectively $/ 11,13 /$. The collective information from all these studies suggests the presence of morphologically and functionally different classes of 5-HT fibers in the brain. Further study will be necessary to clarify whether a specific type of 5-HT fiber mediates the nontransmitter role in facilitating synapse formation.

In conclusion, this study has demonstrated marked differences between 5-HT-mediated synaptic plasticity in the ventral and dorsal horn in the aged chicken. In the ventral horn, 5-HTmediated synaptic plasticity appeared to reach a maximum at about $\mathrm{P} 1 \mathrm{~W}$, remained stable in the young-adult period, and finally disappeared in the aged chicken. By contrast, the results suggested that even in the old chicken, 5-HT fibers in the dorsal horn mediate the trophic influence for synaptic plasticity.

\section{ACKNOWLEDGMENTS}

The authors are grateful to Dr. Ronald W. Oppenheim (Bowman Gray School of Medicine) for a critical reading of the manuscript. The research was supported by Grant-in-Aid for Scientific Research on Priority Areas from the Ministry of Education, Science, and Culture, Japan, and by Research Grant A from the University of Tsukuba.

\section{REFERENCES}

1. Blin J, Baron JC, Dubois B, Crouzel C, Fiorelli M, Attar-Levy D, et al. Loss of brain 5-HT2 receptors in Alzheimer's disease. Brain 1993; 116: 497-510.

2. Bourgeois J-P, Rakic P. Changes of synaptic density in the primary visual cortex of the macaque monkey from fetal to adult stage. J Neurosci 1993; 13: 2801-2820.

3. Chen L, Hamaguchi K, Ogawa M, Hamada S, Okado $\mathrm{N}$. pCPA reduces both monoaminergic afferents and non-monoaminergic synapses in the cerebral cortex. Neurosci Res 1994; 19: 111-115.

4. Chubakov AR, Gromova EA, Konovalov GV, Sarkisova EF, Chumasov EI. The effect of serotonin on the morpho-functional development of rat cerebral cortex in tissue culture. Brain Res 1986; 285-297. 
5. D'Amato RJ, Blue ME, Largen $B L$, Lynch $D R$, Ledbetter DJ, Molliver ME, Snyder SH. Ontogeny of the serotoninergic projection to the rat neocortex: transient expression of a dense innervation to primary sensory areas. Proc Natl Acad Sci USA 1987; 84: 4322-4326.

6. Fujimiya M, Kimura $H$, Maeda T. Postnatal development of serotonin nerve fibers in the somatosensory cortex of mice studied by immunohistochemistry. J Comp Neurol 1986; 246: 191-201.

7. Huttenlocher PR. Synaptic density in human frontal cortex-Developmental changes and effects of aging. Brain Res 1979; 163: 195-205.

8. Huttenlocher PR, de Courten C, Garey LJ, van der Loos H. Synaptogenesis in human visual cortexEvidence for synapse elimnation during normal development. Neurosci Lett 1982; 33: 247-252.

9. Iyo M, Yamasaki T. The detection of age-related decrease of dopamine D1, D2, and serotonin 5-HT2 receptors in living human brain. Prog NeuroPsycopharmacol Biol Psychiat 1993; 17: 415-4 21.

10. Kojima t, Homma S, Sako H, Shimizu I, Okada A, Okado N. Developmental changes in density and distribution of serotoninergic fibers in the chick spinal cord. J Comp Neurol 1988; 267: 580-589.

11. Kosofsky BE, Molliver ME. The serotoninergic innervation of cerebral cortex: Different classes of axon terminals arise from dorsal and median raphe nuclei. Synapse 1987; 1: 153-168.

12. Kristt DA. Development of neocortical circuitry: quantitative ultrastructural analysis of putative monoaminergic synapses. Brain Res 1979; 178: 69-88.

13. Mamounas LA, Molliver ME. Evidence for dual serotoninergic projections to neocortex: Axons from the dorsal and median raphe nuclei are differentially vulnerable to the neurotoxin $\mathrm{p}$-chloroamphetamine (PCA). Exp Neurol 1988; 102: 23-36.

14. Mamounas LA, Mullen CA, O'Hearn E, Molliver ME. Dual serotoninergic projections to forebrain in the rat: Morphologically distinct 5-HT axon terminals exhibit differential vulnerability to neurotoxic amphetamine derivatives. J Comp Neurol 1991; 314: 558-586.

15. Marcusson JO, Morgan DG, Winblad BD, Finch CE. Serotonin-2 binding sites in human frontal cortex and hippocampus. Selective loss of S-2A sites with age. Brain Res 1984; 311: 51-56.

16. Niitsu Y, Hamada S, Hamaguchi K, Mikuni M, Okado N. Regulation of synaptic density by $5-\mathrm{HT} 2 \mathrm{~A}$ receptor agonist and antagonist in the spinal cord of chicken embryo. Neurosci Lett 1995; 195; 159-162.

17. Okado N, Chen L, Tanatsugu Y, Hamada S, Hamaguchi K. Synaptic loss following removal of serotoninergic fibers in newly hatched and adult chickens. J Neurobiol 1993; 24: 687-698.

18. Okado N, Shibanoki S, Ishikawa K, Sako H. Developmental changes in serotonin levels in the chick spinal cord and brain. Dev Brain Res 1989; 50: 217.

19. Ozaki S, Kudo N, Okado N. Immunohistochemical study on development of serotonin-, substance P- and enkephaline-positive fibers in the rat spinal motor nucleus. J Comp Neurol 1992; 325: 462-470.

20. Perry EK, Perry RH, Candy JM, Fairbairn AF, Blessed G, Dick DJ, Tomlinson BE. Cortical serotonin-S2 receptor binding abnormalities in patients with Alzheimer's disease: Comparisons with Parkinson's disease. Neurosci Lett 1984; 51: 353-357.

21. Rakic P, Bourgeois JP, Eckenhoff MF, Zecevic N, Goldman-Rakic PS. Concurrent overproduction of synapses in diverse regions of the primate cerebral cortex. Science 1986; 232: 232-235.

22. Reynolds GP, Arnold L, Rosor AM, Iversen LL, Mountjoy CQ, Roth $M$. Reduced binding of $\left[{ }^{3} \mathrm{H}\right]$-ketanserin to cortical 5HT2 receptors in senile dementia of the Alzheimer type. Neurosci Lett 1984; 44: 47-51.

23. Sako H, Okado N, Kojima T. Immunohistochemical study on the development of sertoninergic neurons in the chick. I. Distribution of cell bodies and fibers in the brain. J Comp Neurol 1986; 253: 61-78.

24. Steinbusch HWM, Wolters MJ, van Luijtelaar MG, Tonnaer JA. The sertoninergic and dopaminergic system in the aged rat brain as studied by immunocytochemistry with antibodies to serotonin and dopamine. Preliminary observation. Newtrend Aging Res 1988; 15: 193-203.

25. van Luijtelaar MG, Steinbusch HWM, Tonnaer JA. Similarities between aberrant sertoninergic fibers in the aged and 5,7-DHT denervated young adult brain. Exp Brain Res 1990; 78: 81-89.

26. van Luijtelaar MG, Tonnaer JA, Steinbusch HW. Aging of the sertoninergic system in the rat forebrain: An immunohistochemical and neurochemical study. Neurobiol Aging 1992; 13: 201-215.

27. Wilson MA, Molliver ME. The organization of serotonergic projections to cerebral cortex in primates: Regional distribution of axon terminals. Neuroscience 1991; 44: 537-553. 

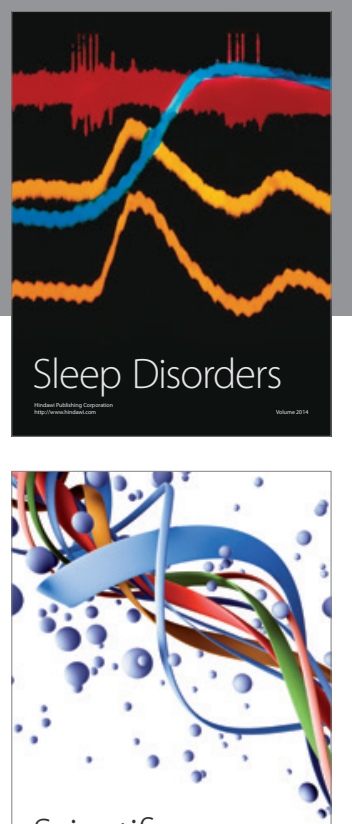

Scientifica
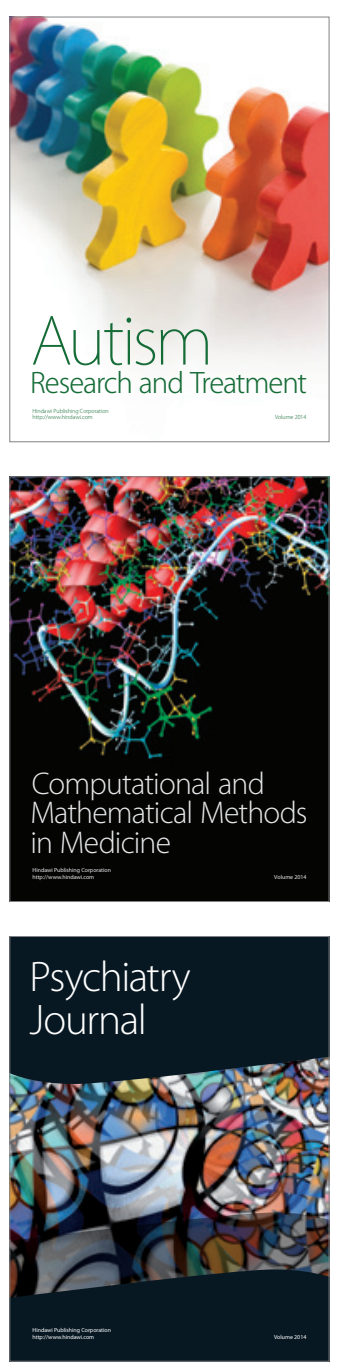
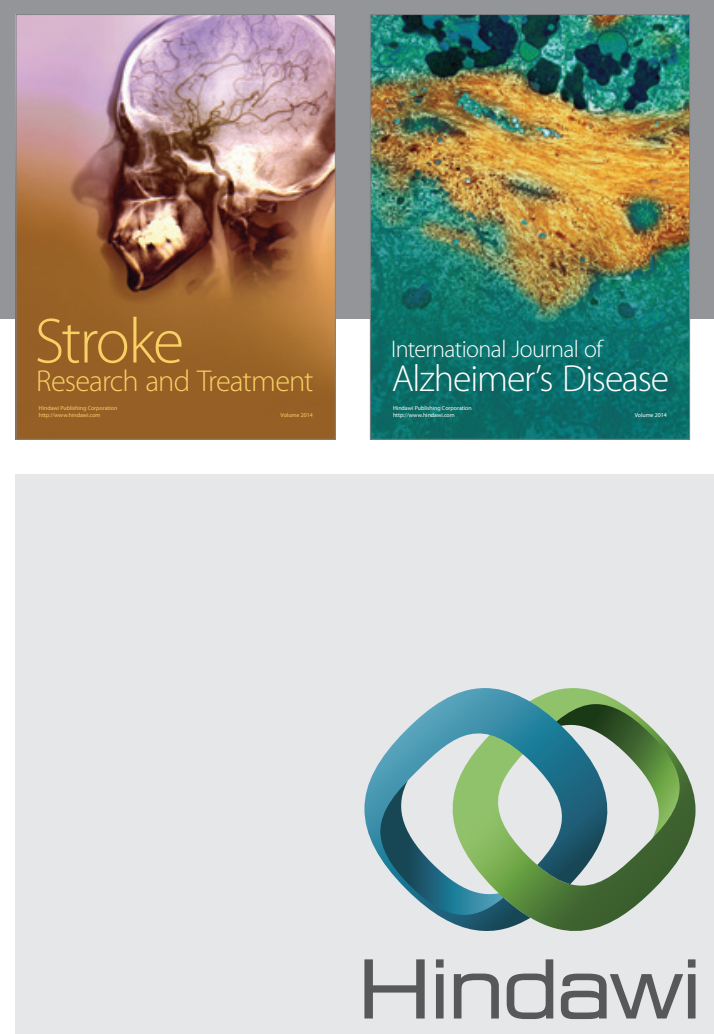

Submit your manuscripts at

http://www.hindawi.com
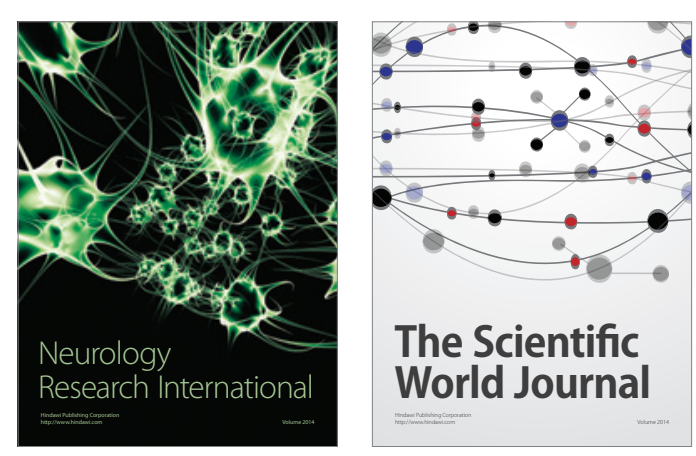

The Scientific World Journal

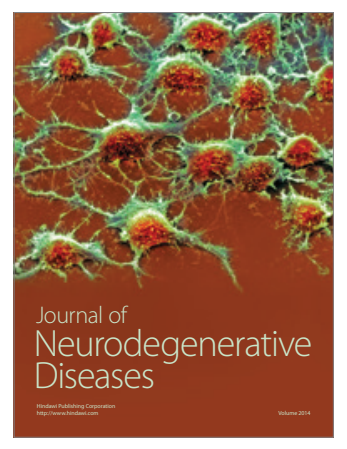

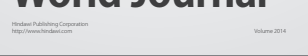

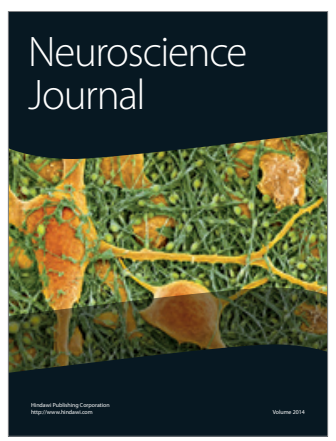

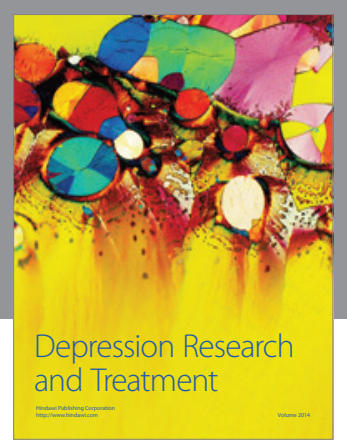
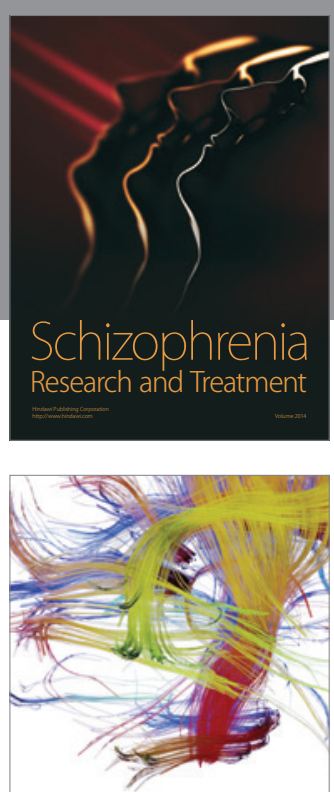

Brain Science

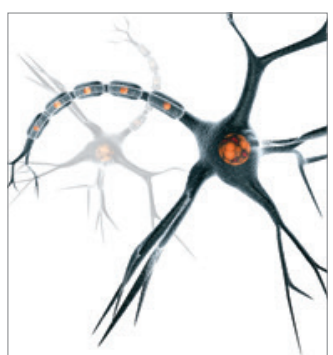

Neural Plasticity
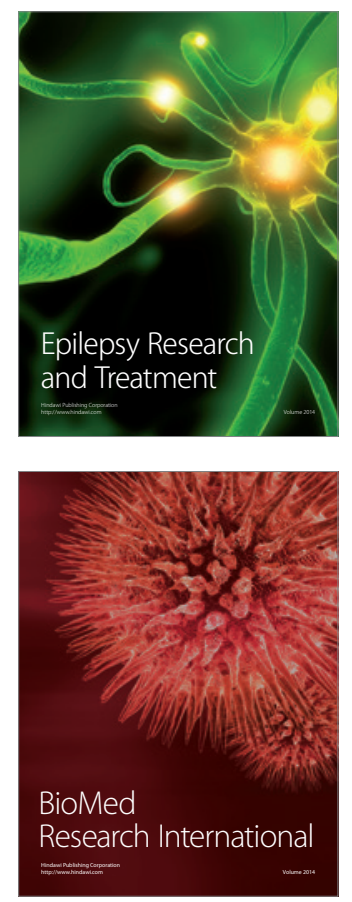

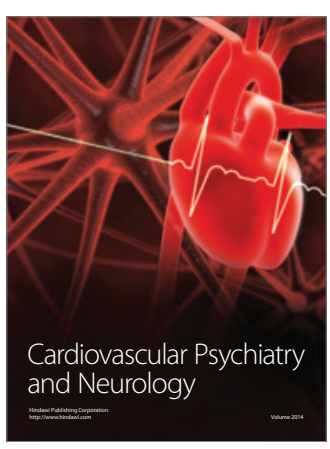

Parkinson's

Disease
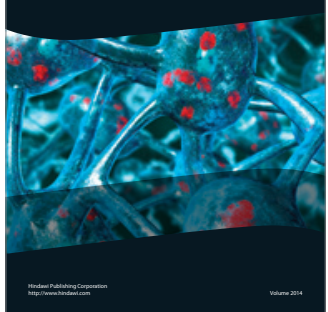